\title{
PARAMETRIC OPTIMIZATION OF METAL INERT GAS WELDING BY USING TAGUCHI APPROACH
}

\author{
Abhishek Prakash ${ }^{1}$, Raj Kumar Bag ${ }^{2}$, Papin Ohdar ${ }^{3}$, Siva Sankar Raju ${ }^{4}$ \\ ${ }^{1}$ Student, Department of Mechanical Engineering, GIET, Gunupur, Odisha, India \\ ${ }^{2}$ Student, Department of Mechanical Engineering, GIET, Gunupur, Odisha, India \\ ${ }^{3}$ Student, Department of Mechanical Engineering, GIET, Gunupur, Odisha, India \\ ${ }^{4}$ Assistant Professor, Department of Mechanical Engineering, GIET, Gunupur, Odisha, India
}

\begin{abstract}
The present work deals with optimization of welding process variables by using Metal inert gas welding. In this process input variables are voltage $(V)$, current $(A)$ and welding speed $(S)$ with tensile properties, hardness, and penetration as responses of low carbon steel (ASTM A29). The design of experiments based on Taguchi orthogonal array [L9], acquires Analysis of variance (ANOVA) to determine the influence of parameters with the optimal condition.
\end{abstract}

Keywords: MIG Welding, Mild Steel, Taguchi Approach, Hardness, Tensile Strength.

\section{INTRODUCTION}

Welding is a process of joining metal parts or we can say it is fabrication process, in which by heating the surfaces of the workpiece with the help of arc (may be mechanical or electrical) or by other means and uniting them by hammering or pressing, etc. We know that MIG welding is one of most versatile technique till now in modern production technology and most importantly, it is suitable for both either for thin sheet or thick section components. Basically, in this process, an electric arc is produced between the consumable wire electrode and the workpiece, due to this heat workpiece metal melts and join. Now in order to protect weld pool from contamination from the atmosphere, i.e. Moisture or oxygen, we are using inert gasses like argon, helium or a mixture of argon-helium or by a mixture of argon-carbon dioxide. While compared to other welding process in this method we are not providing any external filler metal because the wire electrode provides the arc as well act as a filler metal [1]. Now in this experiment we are using mild steel, so basically mild steel means which contain only a small percentage of carbon and also it is strongest and most important it is not easily tempered or hardened. As we know that using high carbon steel it is very difficult to weld, as mild steel is easy to weld and most important fact that most of the people are not aware of this fact that certain types of high carbon steel, for example, stainless steel and special technique are used for welding due to that reason that, it is less brittle than high carbon steels. The mild steel is more flexible than other steel [6]. We all know about that MIG welding, widely used in most of the industry sectors due to its flexibility, deposition rates, and suitability. So, in this era, determination of optimum values of process parameters in the manufacturing industry are the area of greatest interest for either for manufacturing engineers or researchers. Most importantly, this process parameter plays a vital role in determining the quality of a welded joint. There are various parameters will affect the weld ing because this parameter varied over a large extend. Since they are considered as the primary adjustments i.e. tool in any welding process. We all knew that the depth of penetration is the most dominant magnitude related to the weldability of the processes material, the welding conditions, and the strength requirements. Therefore, we have to attempt in such a way that the depth of penetration should be maximized. The most important thing that penetration is indirectly proportional to welding speed and electrode diameter and penetration decreases with the increase in the welding speed because the time during which the arc force is allowed to penetrate into the material's, thus surface decreases [20]. So, the demand for producing joints of dissimilar materials is continuously increasing due to cost reduction and also good mechanical properties. As we discuss earlier that it is extensively used in manufacturing industries due to its simple technique and very easy to learn and use, so welding defects can be minimized easily, as this process, there is no slag and machine can run by automatic or semi-automatic, so less skilled worker can easily complete his task easily, metal deposition rates are high and a lot more advantage than other forms of welding. Their application such as aluminum, copper, stainless steel and carbon steel can be joined with the help of MIG weld ing via suitable electrode, shielding gas and different welding conditions [3-5].

The present work mainly focuses on the weldability of ASTM A29 with the process of MIG welding. The work details of process parameters (welding voltage, welding current and wire speed) influence on the response (Tensile strength and Hardness) by using analysis of variance (ANOVA) with the help of Taguchi array [L9].

\section{LITERATURE REVIEW}

Ajit Hooda et al., 2012 [3] conducted an experiment, in this experiment they are going to develop a response surface 
model to the measured tensile strength of AISI 1040 carbon steel joints of MIG welding. They have chosen process parameters such as voltage, wire speed, current, and gas flow rate. In this experiment, they found that longitudinal strength is more effect than the transverse yield strength. Now for future references they state the relationship between the transverse and longitudinal yield strength by comparing their value and give detail for studying their microstructure.

B. Mishra et al., 2014 [1] conducted an experiment on MIG welding parameter optimization. In this experiment, they present the effect of welding parameters like voltage, speed, current on the depth of penetration on AISI 1020 steel during welding. They made their experiment based on Taguchi technique from where they optimize the welding parameters as well as the process. Finally, they get conduct tests, from where they carried out the difference between the predicted values with the experimental values to find the effective result of analysis of the penetration and finally they got experimental value are for penetration is $5.82 \mathrm{~mm}$ and for $\mathrm{S} / \mathrm{N}$ ratio is 15.01 .

H. J. Park et al., 2008 [4] conducted an experiment. In this experiment, they conducted various wire feed speeds range fro $\mathrm{m} 0.5 \mathrm{~m} / \mathrm{min}$ to $1.5 \mathrm{~m} / \mathrm{min}$ and also the bead characteristics were evaluated and shape factors of the bead width, back bead width, weld bead and bead cross section area are measured. According to their weld quality, the wire speed is optimized by varying welding speed. After the experiments, they found that wire feed speed is optimized at welding speeds of $0.50 \mathrm{~m} / \mathrm{min}$, a. $0 \mathrm{~m} / \mathrm{min}$, and $1.5 \mathrm{~m} / \mathrm{min}$.

Satyaduttsinh P. Chavda et al., 2014 [5] conducted an experiment. They have taken medium carbon steel and optimize the welding parameters. Finally, conduct the test to compare with the predicted number with the experimental number to confirm its results in the analysis of weld strength and depth of penetration.

Vikas Chauhan and Dr. R.S Jadoun in 2014 [6] conducted an experiment.In this method, the analysis for signal-tonoise ratio was done by using the MINITAB-15 software. Finally, they conduct the test to compare the predicted values and experimental values, to confirm its results in the analysis of the tensile strength of the joint. In these experiments, they get an average value of UTS is 549.85 $\mathrm{N} / \mathrm{mm}^{2}$, which is within the confidence interval for the predicted UTS at an optimum level. The percentage error between the predicted value and the experimental value is found in $1.97 \%$.

Diganta and Parimal Bakul Barua in 2015 [7] conducted experiments on Taguchi optimization of MIG welding parameter those are affecting tensile strength of C20 welds. In this experiment, they are going to find out three process parameters of the MIG weld ing i.e. current, voltage and gas flow rate on the tensile strength of welded joints which is having Grade C20 Carbon Steel as the parent metal and ER70S-4 electrode. This experiment was designed by using
Taguchi's Orthogonal Array L9. Finally, conduct the test to predict the mean tensile strength is $475.87 \mathrm{~N} / \mathrm{mm}^{2}$.

Vineeta Kanwal et al., 2015 [2] conducted experiments on optimization of MIG welding parameters for the hardness of alu minum alloys using Taguchi method. The materials used are aluminum alloys of grade 6061 and 5083 having a dimension of $(75 \times 60 \times 6) \mathrm{mm}$. In this experiment Argon gas used as shielding gas. Finally, they found that both alu minum alloys 5083 and 6061 having great hardness, and most important that welding current has more effects on the hardness of welded sample.

S. V Sapakal et al., 2012 [8] conducted an experiment. In this experiment shows the effect of welding parameters like weld ing voltage, current speed on the depth of penetration of MS C20 metal. Finally, conduct the test to compare the predicted numbers with the experimental numbers to confirm its results in the analysis of penetration. Finally, they got the penetration is $5.25 \mathrm{~mm}$ and $\mathrm{S} / \mathrm{N}$ ratio is 14.40 .

Milind M. Ghogale et al., 2013 [9] conducted an experiment. This paper represents an experimental study to investigate the effects of welding parameters, i.e. welding current, voltage, and gas flow rate on cold rolled steel of $3 \mathrm{~mm}$ thick steel strip. From this experiment, they get a conclusion that most influence the parameters on penetration are current and voltage while the gas flow rate is less significant as compared to current and voltage.

Vikas Mukhraiya et al., 2014 [10] conducted an experiment on parametric optimization of MIG welding with the help of Taguchi method. In this paper represent the investigation at the optimization of welding parameters and effect on the torsional rig idity of MIG welded steel of ST-37 rod.

Praful Kumar in 2015 [11] conducted an experiment on parametric optimization of angular distortion on mild steel by using MIG welding. Since it is very difficult to obtain a complete analytical solution to predict the angular distortion in welding. In this experiment, they are using Mild Steel AH36 grade $20 \mathrm{~mm}$ plates. Finally, after the experiment, they conclude that the optimal value of angular distortion is $6.64^{\circ}$ and also that the angular distortion increases with the increase in the number of passes within the design range of the parameters.

Er. Rahul Malik et al., 2015 [12] conducted an experiment on parameter optimization for tensile strength $\&$ hardness of MIG weld ing joint of HSS \& mild steel by using Taguchi technique. In this experiment, they are using high-speed steel of grade M2 and low carbon steel under varying parameters. They finally conclude that Taguchi parametric design process is best suitable for the cost of operation.

Faseeulla et al. (2012) [13] conducted an experiment. Finally, after experiments they get the maximum tensile shear strength of the welded sample. 
G. Haragopal et al. (2011) [14] presented an experiment. This experiment was conducted using the L9 orthogonal array. Finally, a confirmation test was conducted at the optimu m condition to predict correctness of the analysis.

Omar Bataineh et al. (2012) [15] conducted an experiment. After the experiment they set, a conclusion that at voltage 24 $\mathrm{V}$ and filler rate is $7 \mathrm{in} / \mathrm{s}$, at the same time mean weld strength is maximized.

Pawan Kumar et al. (2013) [16] conducted an experiment. They conducted a total nine number of experimental runs using orthogonal array (L9) and finally they get the tensile strength and hardness i.e. WZ and HAZ.

Sudesh Verma et al. (2014) [17] conducted an experiment. In this experiment, they obtain better bead height and bead width separately.

\section{METHODOLOGY}

In this experimental work, as shown in Fig-1, setup of MIG welding, we are going to weld the specimen, the sample is welded at four different levels of welding parameter, i.e. welding current, welding voltage, wire speed as shown in Table 1. Taguchi is a most widely used in manufacturing industry, which is use to predict optimal performance level based on optimal control factor level combination and conduct a confirmation experiment to verify the results product designed. Most important Taguchi Experiments verification is done on the basis of the orthogonal array (L9) technique using MINITAB-16 [18].

Table-1: Welding parameter and their levels

\begin{tabular}{|c|c|c|c|}
\hline Parameters & $\begin{array}{c}\text { Welding } \\
\text { Voltage(V) }\end{array}$ & $\begin{array}{c}\text { Welding } \\
\text { current(A) }\end{array}$ & $\begin{array}{c}\text { Wire } \\
\text { speed }\end{array}$ \\
\hline Units & Volt & Amp & RPM \\
\hline Symbo1 & V & A & S \\
\hline Level 1 & 20 & 200 & 2.2 \\
\hline Level 2 & 22 & 215 & 2.65 \\
\hline Level 3 & 24 & 230 & 3.1 \\
\hline
\end{tabular}

Table-2: Chemical Composition of Low Carbon Steel ASTM A29

\begin{tabular}{|c|c|}
\hline Element & $\%$ \\
\hline Carbon & $0.70-0.80$ \\
\hline Iron, Fe & 98 \\
\hline Manganese, $\mathrm{Mn}$ & $0.40-0.70$ \\
\hline Sulphur, $\mathrm{S}$ & 0.05 \\
\hline Phosphorous, $\mathrm{P}$ & 0.04 \\
\hline
\end{tabular}

In this process, authors are utilized the sample with dimension of $200 \times 100 \times 90 \mathrm{~mm}$ along with groove of $60^{\circ}$ on each face of with help of Hacksaw driven by motor [19]. The chemical composition of Low Carbon steel ASTM A29 is shown in Table-2.

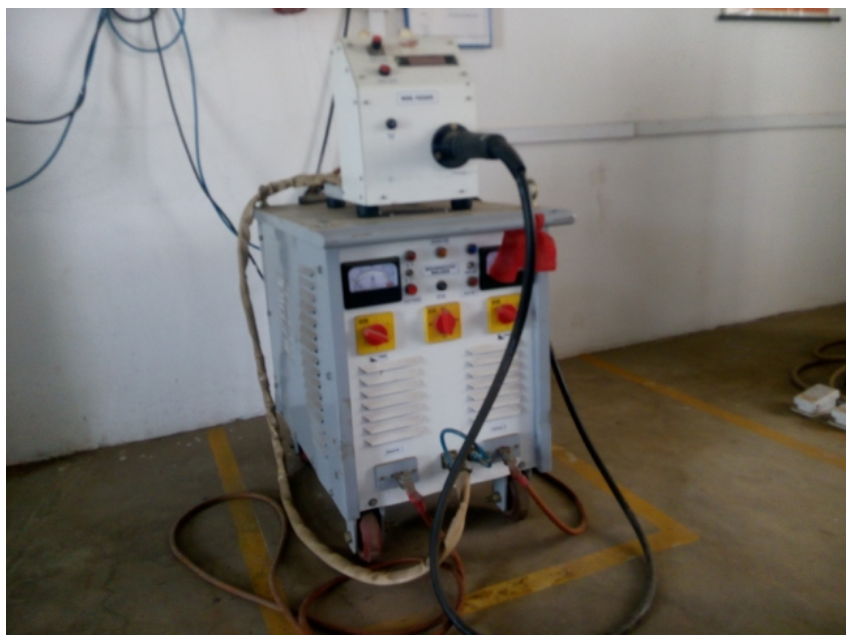

Fig-1: MIG welding setup

Table-3 L9 Orthogonal Array Design matrix

\begin{tabular}{|c|c|c|c|}
\hline Run & V & A & S \\
\hline 1 & 20 & 200 & 2.2 \\
\hline 2 & 20 & 215 & 2.65 \\
\hline 3 & 20 & 230 & 3.1 \\
\hline 4 & 22 & 200 & 2.2 \\
\hline 5 & 22 & 215 & 2.65 \\
\hline 6 & 22 & 230 & 3.1 \\
\hline 7 & 24 & 200 & 2.2 \\
\hline 8 & 24 & 215 & 2.65 \\
\hline 9 & 24 & 230 & 3.1 \\
\hline
\end{tabular}

Total nine experiments were done based on orthogonal array (L9) shown in Table 3. The main effect of different parameters such as welding voltage, current and wire speed of low carbon steel ASTM A29 was analyzed and observed the hardness and tensile strength of all nine weld metal and observed the value of hardness and tensile strength with its $\mathrm{S} / \mathrm{N}$ ratios are predicted in Table 4 . Fig. 2 shows the figure of welded sample.

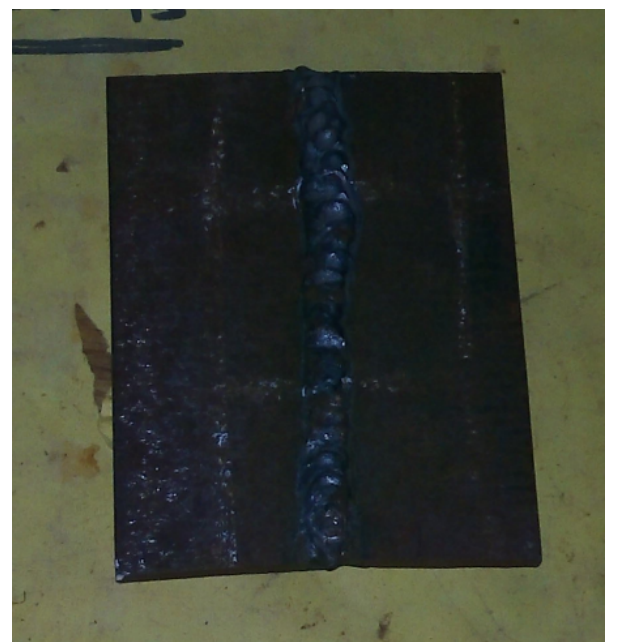

Fig-2: Welded Sample of Low Carbon Steel ASTM A29

For measuring micro-hardness they are first rubbed with emery paper size no. $1 / 0,2 / 0 \& 4 / 0$ and then clean with the help of acetone solution. 
Table- 4: Response of Tensile and Hardness with $\mathrm{S} / \mathrm{N}$ ratio.

\begin{tabular}{|r|r|r|r|r|}
\hline Run & $\begin{array}{l}\text { Tensile } \\
\text { Strength } \\
\text { (Mpa) }\end{array}$ & S/N Ratio & $\begin{array}{l}\text { Hardness } \\
\text { HAZ }\end{array}$ & $\begin{array}{l}\text { S/N } \\
\text { Ratio }\end{array}$ \\
\hline 1 & 351.2 & 50.91109 & 168.5 & 44.532 \\
\hline 2 & 325.2 & 50.243011 & 147.5 & 43.376 \\
\hline 3 & 315.1 & 49.968968 & 156.5 & 43.89 \\
\hline 4 & 481.2 & 53.646512 & 247 & 47.854 \\
\hline 5 & 382.5 & 51.652629 & 189 & 45.529 \\
\hline 6 & 325.6 & 50.253688 & 166.5 & 44.428 \\
\hline 7 & 425.1 & 52.569822 & 219 & 46.809 \\
\hline 8 & 352.2 & 50.935787 & 153.5 & 43.722 \\
\hline 9 & 342.1 & 50.683061 & 179.5 & 45.081 \\
\hline
\end{tabular}

\section{RESULTS AND DISCUSSION}

Fig. 3 predict the various steps in the Taguchi analysis [19]. Analysis of variance (ANOVA) is a statistical tool used to analyze the S/N ratios. We also know that the term "signal" represents the desirable mean value, and the "noise"undesirable value. Hence, we can say that $\mathrm{S} / \mathrm{N}$ ratio show the amount of variation, which is presented in the performance characteristics.

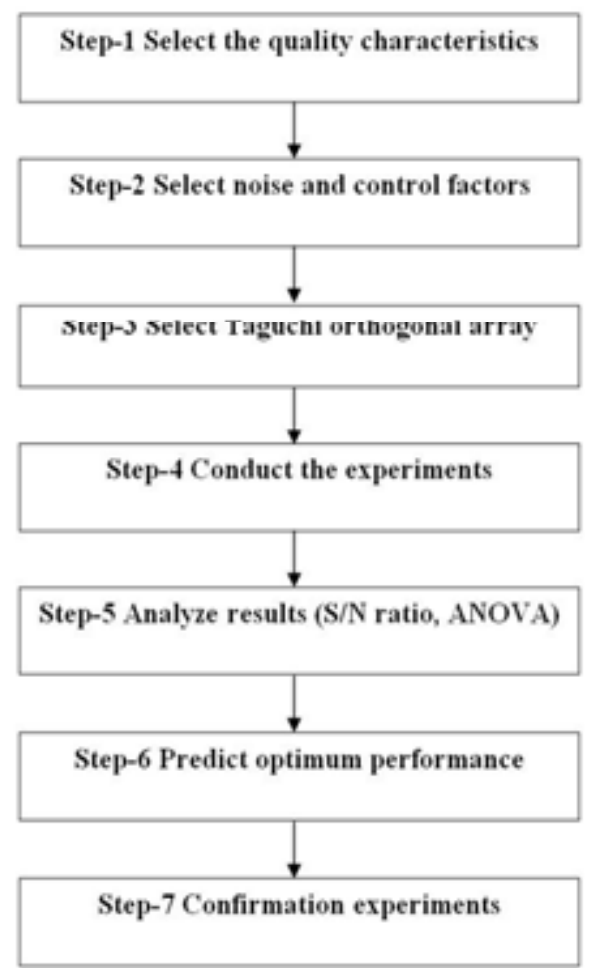

Fig-3: Steps of Taguchi's Analysis

\subsection{ANOVA of Tensile Strength}

In this experiment, Tensile strength is calculated experimentally and Taguchi method is used for the analys is with the help of ANOVA (L9). According to data are found, we get a graph of the signal-to-noise $(\mathrm{S} / \mathrm{N})$ ratio is shown in Fig-4. The calculated $\mathrm{S} / \mathrm{N}$ ratio is shown in Table 4.

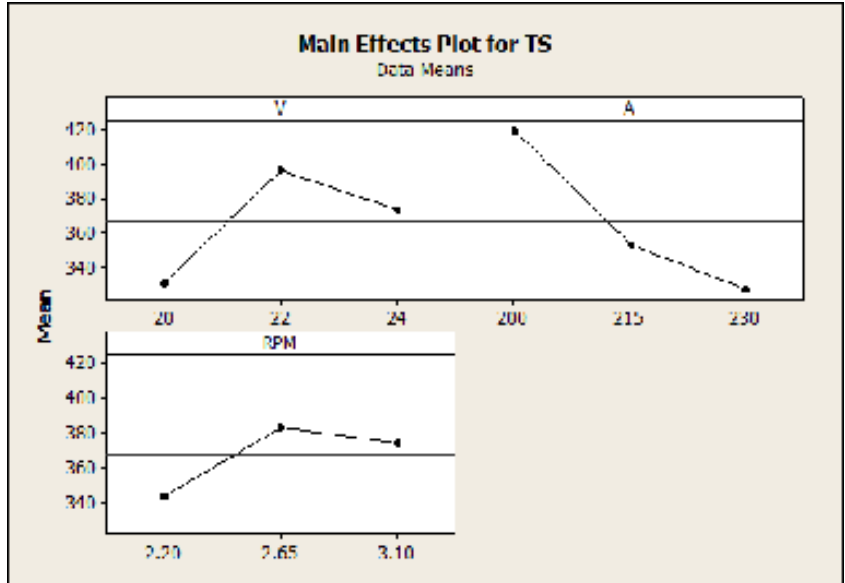

Fig-4: Main Effects plot of process parameters on tensile strength for $\mathrm{S} / \mathrm{N}$ ratio

The ANOVA is one of the most widely used methods for portioning variability into an identifiable source of variation and the associated DOF in an experiment. F-test for analyze the significant effects of the process parameters, which form quality characteristics. In Table-5 show, the result of ANOVA analysis of S/N ratio of low carbon steel ASTM A29.the ANOVA obtained $\mathrm{R}^{2}$ and $\mathrm{R}_{\mathrm{adj}}{ }^{2}$ as 96.3 and $85.2 \%$. The ANOVA revealed the influence of process parameters with a response. Welding current $(\mathrm{A})$ is the most influencing parameter $(57.25 \%)$ and followed by the welding voltage (V) as $(29.05 \%)$ and wire speed as $10 \%$. The influence of parameters such as voltage, current, and wire speed was analyzed on table-6. It is observed that the process parameters with the greater $\mathrm{S} / \mathrm{N}$ ratio will have optimum quality with less variance.

Table-5: Analysis of Variance for Signal to Noise Ratio of tensile strength

\begin{tabular}{|l|c|l|l|l|l|l|}
\hline Source & DF & Seq Ss & $\begin{array}{l}\text { Adj } \\
\text { SS }\end{array}$ & $\begin{array}{l}\text { Adj } \\
\text { MS }\end{array}$ & F & P \\
\hline V & 2 & 3.4313 & 3.4313 & 1.7156 & 7.84 & 0.113 \\
\hline A & 2 & 6.7637 & 6.7637 & 3.3819 & 15.46 & 0.061 \\
\hline S & 2 & 1.1809 & 1.1809 & 0.5904 & 2.70 & 0.270 \\
\hline Error & 2 & 0.4376 & 0.4376 & 0.2188 & & \\
\hline Total & 8 & 11.8135 & & & & \\
\hline
\end{tabular}

The response value for $\mathrm{S} / \mathrm{N}$ ratio is shown in Table-6 which shows their ranking and factors level values of each factor. From the response tables, the optimal condition for Tensile strength as the welding current (A3) is a dominant parameter on the tested specimens, followed by welding voltage (V1) and wire speed (S1). The ranking of the parameters is shown in Table 6. This refers the optimal condition of Tensile strength as V1A3S1. 
Table-6: Response Table for S/N Ratio for Tensile Strength

\begin{tabular}{|l|l|l|l|}
\hline LEVEL & V & A & S \\
\hline 1 & 50.37 & 52.38 & 50.70 \\
\hline 2 & 51.85 & 50.94 & 51.52 \\
\hline 3 & 51.40 & 50.30 & 51.40 \\
\hline DELTA & 1.48 & 2.07 & 0.82 \\
\hline RANK & 2 & 1 & 3 \\
\hline
\end{tabular}

\subsection{ANOVA of Hardness}

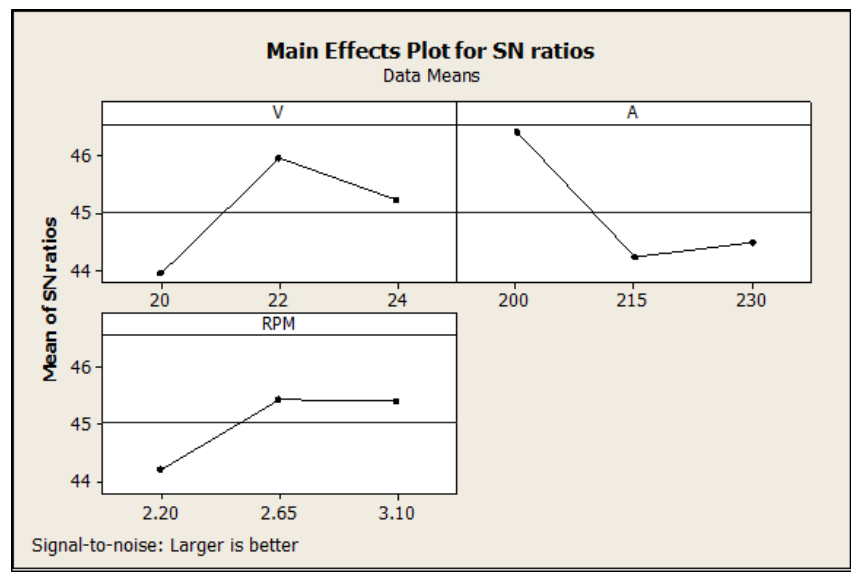

Fig-5: Effects of process parameter on hardness $\mathrm{S} / \mathrm{N}$ ratio

From Fig. 5 it was observed that the welding voltage (20 volts), welding current (215 amp), and wire speed (2.2) gives an optimal Hardness. We know that the $\mathrm{S} / \mathrm{N}$ ratio for each parameter was determined by averaging the $\mathrm{S} / \mathrm{N}$ ratios at the corresponding level. The effect of parameters such as welding voltage, welding current, and wire speed was analyzed on Table-4. It is observed that the process parameters with the greatest $\mathrm{S} / \mathrm{N}$ ratio have optimu m quality with less variance.

The ANOVA obtained $\mathrm{R}^{2}$ and $\mathrm{R}_{\mathrm{adj}}{ }^{2}$ as 99.3 and $97.2 \%$. The ANOVA revealed the influence of process parameters with a response. Welding current (A) is the most influencing parameter $(48.14 \%)$ and followed by the welding voltage (V) as $(34.78 \%)$ and wire speed as $16.12 \%$.

Table-7: Analysis of Variance for Signal to Noise Ratio of Hardness

\begin{tabular}{|l|l|l|l|l|l|l|}
\hline So urce & DF & Seq Ss & Adj SS & Adj MS & F & P \\
\hline V & 2 & 6.1716 & 6.1716 & 3.08581 & 49.88 & 0.020 \\
\hline A & 2 & 8.5902 & 8.5902 & 4.29509 & 69.43 & 0.014 \\
\hline S & 2 & 2.8608 & 2.8608 & 1.43042 & 23.12 & 0.041 \\
\hline Residual & 2 & 0.1237 & 0.1237 & 0.06186 & & \\
\hline Total & 8 & 17.7463 & & & & \\
\hline
\end{tabular}

From response table, we can predict that the wire speed is a dominant parameter on the tested specimens, followed by welding voltage and welding current. The ranking of the parameters is shown in Table 8. From the response tables, the optimal condition for Tensile strength as the welding current (A2) is a dominant parameter on the tested specimens, followed by welding voltage (V1) and wire speed (S1). This refers the optimal condition of the Hardness as V1A2S1.
Table-8: Response Table for S/N Ratio for Hardness

\begin{tabular}{|l|l|l|l|}
\hline Le vel & V & A & S \\
\hline 1 & 43.93 & 46.4 & 44.23 \\
\hline 2 & 45.94 & 44.21 & 45.44 \\
\hline 3 & 45.2 & 44.47 & 45.41 \\
\hline Delta & 2 & 2.19 & 1.21 \\
\hline Rank & 2 & 1 & 3 \\
\hline
\end{tabular}

\subsection{Multiple Line ar Regression Mode Is:}

Multiple linear regression equations were developing a relation between the process variables and response. The value of regression coefficient $R^{2}(0.963)$ is in good agreement with the adjusted $\mathrm{R}^{2}(0.852)$ for the Tensile strength of the ASTM A29. $\mathrm{R}^{2}(0.993)$ is in good agreement with the adjusted $R^{2}(0.972)$ for the Hardness of the ASTM A29. Considering that both values are close to unity, this model gives a good result between the independent parameters and responses.

The regression equation developed for the surface roughness of the Tensile strength is as follows:

$\mathrm{TS}=696+10.7 \mathrm{v}-3.05 \mathrm{~A}+34.7 \mathrm{~S}$

The regression equation developed for the Hardness of ASTM A29 is as follows:

$\mathrm{HS}=276+6.62 \mathrm{v}-1.47 \mathrm{~A}+28.1 \mathrm{~S}$

We can predict from Equations. (1) \& (2) that the Welding Current (A) plays a greater role on Tensile and Hardness, followed by welding voltage $(\mathrm{V})$ and wire speed (S). The coefficient associated with welding current (A) is negative, thus indicating that the Tensile and hardness as decreases with increasing welding current. Conversely, the Tensile and hardness increase with increasing welding voltage and wire speed because the coefficients of these factors are positive. Wire speed has a greater effect on Tensile and hardness as compared with other parameters according to its coefficient value in the welding of MIG.

\subsection{Confirmation Test}

The confirmation test is the last step in the experiment. The confirmation test is shown in Table 9.

Table-9: Conformation Test

\begin{tabular}{|c|l|l|r|l|l|r|}
\hline & \multicolumn{3}{|c|}{ T S } & \multicolumn{3}{c|}{ HS } \\
\hline Exp Run & Cal. & Exp. & Error & Cal. & Exp. & Error \\
\hline 1 & 376.3 & 351.2 & -7.16 & 176.2 & 168.5 & 4.38 \\
\hline 3 & 316.1 & 315.1 & -0.31 & 157.4 & 156.5 & 0.58 \\
\hline 5 & 367.6 & 382.5 & 3.89 & 180.1 & 189.0 & -4.97 \\
\hline 6 & 337.5 & 325.6 & -3.65 & 170.7 & 166.5 & 2.43 \\
\hline 9 & 358.9 & 342.1 & -4.90 & 183.9 & 179.5 & 2.39 \\
\hline
\end{tabular}


The $\%$ of error determined with ratio of the difference of actual and predicted to actual once. As shown in Table 9, the $\%$ of error less than $( \pm 5 \%)$ which is significant.

\section{CONCLUSIONS}

The investigation results show that

1. The Welding Current has the greatest influence on Tensile and Hardness in the Weldability of ASTM A29 followed by welding voltage and wire speed.

2. The optimal conditional for Tensile strength as the weld ing current (250) is a dominant parameter on the tested specimens, followed by welding voltage (20) and wire speed (2.2).

3. The optimal condition of Hardness, such as the welding voltage (20 volts), welding current (215 a mp), and wire speed (2.2) can be used to achieve better hardness in ASTM A29.

\section{REFERENCES}

[1]. B. Mishra, R.R. Panda and D. K. Mohanta.(2014): Metal Inert Gas (Mig) Welding Parameters Optimization, International Journal of Multidisciplinary and Current Research, Vol.2 (May/June 2014 issue).

[2]. Vineeta Kanwal and R S Jadoun.(2015): Optimization of MIG Welding Parameters for Hardness of Aluminium Alloys Using Taguchi Method, SSRG International Journal of Mechanical Engineering (SSRG-IJME), vol.2, Issue 6, pp. 53-56.

[3]. Ajit Hooda, Ashwani Dhingra and Satpal Sharma.(2012): Optimization of Mig Welding Process Parameters To Predict Maximum Yield Strength in AISI 1040, International journal of mechanical engineering and robotics research, Vol.1 No. 3, October 2012.

[4]. H.J. Park , D.C. Kim, M.J. Kang and S. Rhee.(2008): Optimization of the Wire Feed Rate During Pulse MIG Welding of Al Sheets, Journal of Achievements in Materials and Manufacturing Engineering, Vol.27, Issue 1 March 2008.

[5]. Satyaduttsinh P. Chavda, Jayesh V.Desai, and Tushar M.Patel.(2014): A Review on Optimization of MIG Weld ing Parameters using Taguchi's DOE Method, International Journal of Eng ineering and Management Research, Volume4, Issue-1, February-2014, pp. 16-21.

[6]. Vikas Chauhan and Dr. R. S. Jadoun.(2014): Parametric Optimization of Mig Welding For Stain less Steel (Ss-304) And Low Carbon Steel Using Taguchi Design Method, International Journal of Advanced Technology \& Engineering Research (IJATER), 1st International Conference on Research in Science, Engineering \& Management (IOCRSEM 2014) 224.

[7]. Diganta Kalita and Parimal Bakul Barua.(2015): Taguchi Optimization of MIG Welding Parameters Affecting Tensile Strength of C20 Welds, International Journal of Engineering Trends and Technology (IJETT), Vol 26 No 1- August 2015 pp. 43.

[8]. S. V. Sapakal and M. T. Telsang.(2012): Parametric Optimization of Mig Welding Using Taguchi Design Method, International Journal of Advanced Engineering
Research and Studies, vol.1, Issue IV/July-Sept., 2012, pp. 28-30.

[9]. Milind M. Ghogale and Prof. S. A. Patil.(2013): Optimisation of Process Parameters of Mig Welding To Improve Quality of Weld By Using Taguchi Methodology, International Journal of Engineering Research \& Technology (IJERT), Vol. 2, Is sue 12, December - 2013.

[10]. Vikas Mukhraiya , Raj Kumar Yadav, and Sanjay Jathar.(2014): Parametric Optimization of MIG Welding Process with the Help of Taguchi Method, International Journal of Engineering Research \& Technology (IJERT), Vol. 3 Issue 1, January - 2014.

[11]. Praful Kumar.(2015): Parametric Optimization of Angular Distortion On Mild Steel By Using Mig Welding, International Journal of Advanced Engineering Technology, Vol. VI, Issue IV Oct.-Dec.,2015, pp.41-46.

[12]. Er. Rahul Malik, Er. Surjeet Gahlot and Dr. S.K. Jarial.(2015): Parameters Optimization for Tensile Strength \& Hardness of MIG Weld ing Joint of HSS \& Mild Steel by Using Taguchi Technique, International Journal of Enhanced Research in Science, Technology \& Engineering, , Vol. 4, Issue 8, August-2015, pp. 84-95.

[13]. Faseeulla Khan M D, Dwivedi D K and Satpal Sharma.(2012): Development of Response Surface Model for Tensile Shear Strength of Weld-Bonds of Aluminium Alloy 6061 T651, Materials and Design, Vol. 34, pp. 673678.

[14]. G. Haragopal, , P V R Ravindra Reddy, G Chandra Mohan Reddy and J V Subrahmanyam.(2011): Parametric design for MIG welding of Al-65032 alloy using Taguchi Technique, Journal of Scientific and Industrial Research, Vol. 70, October 2011, pp.844-858.

[15]. Omar Bataineh, Anas Al-Shoubaki and Omar Barqawi, Optimizing Process Conditions in MIG Welding of Aluminum Alloys Through Factorial Design Experiments, Latest Trends in Environmental and Manufacturing Engineering, ISBN: 978-1-61804-135-7.

[16]. Pawan Kumar.(2013): Parametric Optimization of Gas Metal Arc Welding of Austenitic Stain less Steel (AISI 304) \& Low Carbon Steel using Taguchi's technique, International Journal of Engineering Research and Management research, Vol. 3, Issue 4, Aug 2013, pp.1822.

[17]. Sudesh Verma and Rajdeep Singh.(2014): Optimization of Process Parameters of Metal Inert Gas Welding By Taguchi Method On CRC Steel IS 513 GR -D, International Journal of Advance Research In Science And Engineering IJARSE, vol. 3 (9), September 2014, pp. 187 197.

[18]. Siva Sankar Raju, G Srinivasa Rao and Dr. M Muralidhara Rao.(2015): Optimization Of Machinability Properties On Alu minium Metal Matrix Composite Prepared By In-Situ Ceramic Mixture Using Coconut Shell AshTaguchi Approach, International Journal of Conceptions on Mechanical and Civil Engineering, Vol. 3, Issue 2, Aug 2015.

[19]. Rakesh kumar and Satish kumar.(2014): Study Of Mechanical Properties In Mild Steel Using Metal Inert Gas Welding, International Journal of Research In Engineering And Technology, Vol. 3, Issue 4 April 2014. 
[20]. Er. Rahul Malik, Er. Surjeet Gahlot and Dr. S.K. Jarial.(2015): Parameters Optimization for Tensile Strength \& Hardness of MIG Weld ing Joint of HSS \& Mild Steel by Using Taguchi Technique, International Journal of Enhanced Research in Science, Technology \& Engineering, Vol. 4, Is sue 8, August-2015.

\section{BIOGRAPHIES}

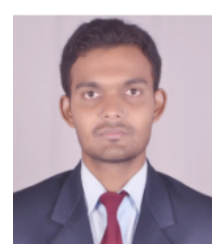

Abhishek Prakash pursuing his B. Tech (Mechanical Engineering) from Gandhi Institute of Engineering and Technology, Gunupur-765022, Odisha, India.

Email Id:

abhishek99prakash44@gmail.com

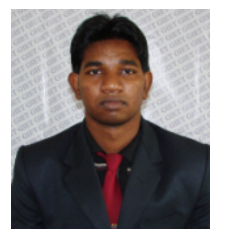

Raj Kumar Bag pursuing his B. Tech (Mechanical Engineering) from Gandhi Institute of Engineering and Technology, Gunupur-765022, Odisha, India.

Email Id: giet12me044@gmail.com

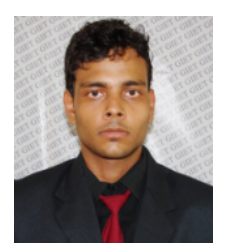

Papin Ohdar pursuing his B. Tech (Mechanical Engineering) from Gandhi Institute of Engineering and Technology, Gunupur-765022, Od isha, India.

Email Id: giet12 me043@gmail.com

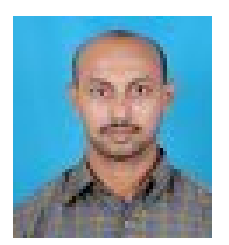

Siva Sank ar Raju joined the teaching faculty in the department of Mechanical Engineering, Gandhi Institute of Engineering and Technology, Gunupur765022, Odisha, India over 8 years back. He obtained his $M$. Tech from Acharya Nagarjuna University.

Email Id:sivaraju80@gmail.com 